REVIEW ARTICLE

\author{
R.G. Nogueira \\ L.H. Schwamm \\ J.A. Hirsch
}

\title{
Endovascular Approaches to Acute Stroke, Part 1: Drugs, Devices, and Data
}

SUMMARY: Despite years of research and pioneering clinical work, stroke remains a massive public health concern. Since 1996, we have lived in the era of US Food and Drug Administration-approved intravenous (IV) recombinant tissue plasminogen activator (rtPA). This treatment, despite its promise, continues to exhibit its limitations. Endovascular therapy has several theoretic advantages over IV rtPA, including site specificity, longer treatment windows, and higher recanalization rates. In this article, we will review the various pharmacologic strategies for acute stroke treatment, providing both a historic context and the state of the art. The drugs will be classified on the basis of their theoretic rationale for therapy. Next, we will review the various devices and strategies for mechanical revascularization with an aim toward comprehensiveness. These range from wire disruption of thrombus to preclinical trials for novel mechanical solutions. This first installment of this 2-part series will end with an analysis of retrograde reperfusion techniques.

C omposing a review article on the endovascular management of stroke is a daunting task. Despite years of wellintentioned providers working diligently to treat this terrible disease, limited consensus exists even within our own community as to appropriate use of these techniques. Data range from preclinical through small single-center case series all the way up to large multicenter randomized control trials. Concurrently, and in part due to, there has been a crescendo in the pace of drug and device development during the past few years. Part 1 of this 2-part series is a comprehensive review and meaningful classification of the drugs and devices that have been relevant historically, a part of treatment in 2009, or a part of the present discussion of treatment options going forward.

\section{Overview and Rationale for Endovascular Stroke Therapy}

Stroke remains the third most common cause of death in industrialized nations, after myocardial infarction and cancer, and the single most common reason for permanent disability. ${ }^{1}$ Each year approximately 780,000 Americans experience a new or recurrent stroke. Approximately 1 in 4 people die within 1 year after having an initial stroke. This means that on average, every 40 seconds someone in the United States has a stroke and every 3-4 minutes someone in the United States dies from a stroke. $^{2}$ Moreover, 30\%-50\% of stroke survivors do not regain functional independence and $15 \%-30 \%$ of all stroke survivors are permanently disabled (ie, not able to walk, talk clearly, or feed themselves with a favored hand). Thus stroke demands a massive financial and personal burden on our society. Indeed, the estimated direct and indirect cost of stroke for 2008 adds up to approximately 65.5 billion dollars. ${ }^{2}$

From the Endovascular Neurosurgery/Interventional Neuroradiology Section (R.G.N., J.A.H.), Departments of Radiology and Neurosurgery, and Neurocritical Care and Vascular Neurology Section (R.G.N., L.H.S.), Department of Neurology, Massachusetts General Hospital, Harvard Medical School, Boston, Mass.

R.G.N. is a member of the Physician Advisory Boards and Speaker Bureau for Concentric Medical, ev3 Neurovascular, and Coaxia. He is also a member of the Steering Committee of the RETRIEVE trial and the principal investigator for the DAWN trial. L.H.S. is a consultant for Coaxia. J.A.H. is a member of the Steering Committee of the Merci Registry.

Please address correspondence to: Raul G. Nogueira, MD, Department of Interventional Neuroradiology and Endovascular Neurosurgery, Massachusetts General Hospital, 55 Fruit St, GRB-2-241, Boston, MA, 02114; e-mail: rnogueira@partners.org

Indicates open access to non-subscribers at www.ajnr.org

DOI 10.3174/ajnr.A1486
In 1996, the US Food and Drug Administration (FDA) approved intravenous (IV) thrombolysis with recombinant tissue plasminogen activator (rtPA, alteplase) for the treatment of acute ischemic stroke within 3 hours of onset after reviewing the results of the National Institute of Neurological Disorder and Stroke (NINDS) and rtPA Stroke Study Group trial. ${ }^{3}$ IV rtPA thrombolysis was the first approved treatment for acute stroke that effectively treats the causative vascular occlusion and, hence, was a landmark development. This strategy has the advantage of being relatively easy and rapid to initiate and does not require highly specialized equipment or technical expertise. Even though IV thrombolysis was initially a matter of relative controversy, it has now been endorsed as a class IA level of evidence intervention by the major national guidelines development organizations. ${ }^{4,5}$

A Cochrane Database Review including 18 trials (16 double-blind) with a total of 5727 patients who received thrombolytics (IV urokinase, streptokinase, rtPA, or recombinant intra-arterial prourokinase) up to 6 hours after ischemic stroke showed a significant reduction in the proportion of patients who were dead or dependent (modified Rankin Scale [mRS] score, 3-6) at follow-up at 3-6 months (odds ratio [OR], 0.84; 95\% confidence interval [CI], 0.75-0.95), despite a significant increase in the odds of death within the first 10 days (OR, 1.81; 95\% CI, 1.46-2.24); most of the deaths were related to symptomatic intracranial hemorrhage $(\mathrm{sICH})(\mathrm{OR}$, $3.37 ; 95 \%$ CI, 2.68-4.22). ${ }^{6}$ In addition, a pooled analysis of 6 major randomized placebo-controlled IV rtPA stroke trials (Alteplase Thrombolysis for Acute Noninterventional Therapy in Ischemic Stroke [ATLANTIS] I and II, European Cooperative Acute Stroke Study [ECASS] I and II, and NINDS I and II), including 2775 patients who were treated with IV rtPA or a placebo within 360 minutes of stroke onset, confirmed the benefit up to 3 hours and suggested a potential benefit beyond 3 hours for some patients. ${ }^{7}$ The pattern of a decreasing chance of a favorable 3-month outcome as the time interval from stroke onset to start of treatment increases was consistent with the findings of the original NINDS study. The benefit of IV rtPA in the 3- to 4.5-hour window was subsequently confirmed by the ECASS-III trial in a somewhat narrower subgroup of patients than those in whom IV rtPA is approved for treatment within 3 hours of onset. ${ }^{8}$

Nonetheless, IV thrombolysis is not a panacea for acute 
Recanalization or antegrade

IV and/or IAT

Endovascular thrombectomy

Endovascular thromboaspiration

Mechanical thrombus disruption

Transcranial or endovascular augmented fibrinolysis

Endovascular thrombus entrapment

Temporary endovascular bypass

Alternative

Global reperfusion (flow augmentation or

transarterial retrograde reperfusion)

Transvenous retrograde reperfusion (flow reversal)
Thrombolytic agents: plasminogen activators, direct fibrinolytics, fibrinogenolytic agents; adjunctive therapy: heparin, direct thrombin inhibitors, GP Ilb/Illa antagonists

Distal devices: Merci, ${ }^{*}$ Phenox, Neuronet, Catch, Attractor-18; proximal devices: Alligator, In-Time Retriever, snares Penumbra, ${ }^{*}$ AngioJet, F.A.S.T. Funnel Catheter

Microguidewire, snares, balloon angioplasty, OmniWave

Transcranial Doppler, EKOS MicroLysUS, OmniWave

SES and balloon-expandable stents

Resheathable (closed-cell) stents, ReVasc

Pharmacologic: vasopressors (eg, phenylephrine); mechanical: NeuroFlo

Partial: retrograde transvenous neuroperfusion; complete: ReviveFlow

Note:-IV indicates intravenous; IAI, intra-arterial thrombolysis; GP IIb/IIla, glycoprotein Ilb/IIla; SES, self-expanding stents.

* The Merci retriever and Penumbra systems have been approved by the FDA to "remove blood clots from the brain in patients experiencing an ischemic stroke." The remaining drugs and devices constitute off-label and/or investigational (preclinical or clinical) usage.

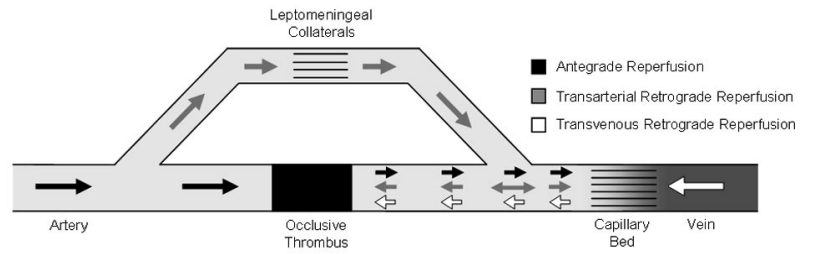

Fig 1. Schematic illustration of the cerebral vascular bed demonstrates the different reperfusion approaches, some of which remain experimental.

stroke treatment. The recanalization rates of IV rtPA for proximal arterial occlusion range from only $10 \%$ for internal carotid artery (ICA) occlusion to $30 \%$ for proximal middle cerebral artery (MCA) occlusion. ${ }^{9}$ Analysis of the NINDS trial data shows a $12 \%$ absolute increase in good outcomes between the placebo and rtPA groups at 3 months. ${ }^{10}$ In other words, 8 patients with stroke must be treated with rtPA to achieve 1 additional good patient outcome. However, this oft-quoted critique understates the impact of rtPA on the patient with stroke because it fails to include patients who partially improved with IV rtPA. ${ }^{11}$ Indeed, an analysis based on the shift in mRS scores suggests a number needed to treat of 3 for any improvement with IV rtPA. ${ }^{12}$ That having been said, even when considering this argument in support of a more generous interpretation of the NINDS data, we should acknowledge that rates of improvement remain far from ideal, and given the prevalence and impact of acute ischemic stroke, it is imperative to devise strategies that can be more effective. Our thesis is based on the implicit assumption that faster more complete reperfusion will translate into better long-term patient outcomes. There are 3 types of reperfusion strategies: 1) recanalization or antegrade reperfusion, 2) global reperfusion (flow augmentation or transarterial retrograde reperfusion), and 3) transvenous retrograde reperfusion (flow reversal) (Table and Fig 1).

\section{Recanalization or Antegrade Reperfusion Strategies}

Recanalization strategies focus on removing and/or dissolving the occlusive thrombus to re-establish antegrade flow. This can be accomplished through the use of thrombolytics, mechanical devices, or their combination. The recanalization strategies may be classified into 7 different categories on the basis of their primary mechanism of action: 1) IV and/or intraarterial thrombolysis (IAT), 2) endovascular thrombectomy, 3) endovascular thromboaspiration, 4) endovascular mechanical thrombus disruption or thromborrhexis, 5) transcranial or endovascular augmented fibrinolysis, 6) endovascular thrombus entrapment, and 7) temporary endovascular bypass.

\section{IAT in Acute Ischemic Stroke}

IAT has several theoretic advantages over IV thrombolysis. For instance, with the coaxial microcatheter techniques, the occluded intracranial vessel is directly accessible and the fibrinolytic agent can be infused directly into the thrombus. This permits a smaller dose of fibrinolytic agent to reach a higher local concentration than that reached by systemic infusion and ideally allows more complete recanalization with lower total doses of thrombolytic. With the smaller dose, complications from systemic fibrinolytic effects, including intracranial hemorrhage $(\mathrm{ICH})$, can theoretically be reduced. For these reasons, the treatment window for endovascular techniques can be extended beyond the typical IV window of 3 hours. This factor becomes particularly important in face of the relatively low number of patients who present within the time window for IV rtPA. ${ }^{13,14}$ IA techniques have led to higher recanalization rates than IV thrombolysis. ${ }^{15}$ As with other endovascular recanalization techniques, the major disadvantages to IAT include the relative complexity of the procedure, the level of required technical expertise and its relatively low availability, delays in initiating treatment, and the additional risks and expense of an invasive procedure compared with IV rtPA.

Thrombolytic Agents: Plasminogen Activators. These drugs act by converting the inactive proenzyme, plasminogen, into the active enzyme, plasmin. Plasmin digests fibrinogen, fibrin monomers, and cross-linked fibrin (as found in a thrombus) into fibrin degradation products. The plasminogen activators vary in stability, half-life, and fibrin selectivity. The thrombolytics that have been reported for use in stroke IAT include urokinase, alteplase, reteplase, prourokinase, and streptokinase. ${ }^{16,17}$ In general, the nonfibrin-selective drugs 
(eg, urokinase and streptokinase) can result in systemic hypofibrinogenemia, whereas the fibrin-selective agents (eg, rtPA and r-prourokinase) are mostly active at the site of thrombosis.

First-Generation Agents. Streptokinase, a protein derived from group C $ß$-hemolytic streptococci, has a half-life of 16-90 minutes and low fibrin specificity. This drug proved to have a very narrow therapeutic window and significant rates of $\mathrm{ICH}$ and systemic hemorrhage ${ }^{18}$; thus, it is no longer used for stroke IAT. Urokinase is a serine protease with a plasma halflife of 14 minutes and low fibrin specificity. The urokinase dose used in cerebral IAT has ranged from 0.02 to $2 \times 10^{6}$ units. $^{16}$

Second-Generation Agents. Alteplase (rtPA) is a serine protease with a plasma half-life of 3.5 minutes and a high degree of fibrin affinity and specificity. The rtPA dose used in cerebral IAT has ranged between 20 and $60 \mathrm{mg} .{ }^{16}$ The theoretic disadvantages of alteplase include its relatively short halflife and limited penetration into the clot matrix because of strong binding with surface fibrin, which could delay recanalization and increase the risk of recurrent occlusion. Additionally, rtPA appears to have some neurotoxic properties, including activation of metalloproteinases, which may result in increased blood-brain barrier permeability leading to cerebral hemorrhage and edema and amplification of calcium currents through the $N$-methyl D aspartate receptor, leading to excitotoxicity and neuronal death. ${ }^{19}$ Prourokinase (r-prourokinase) is the proenzyme precursor of urokinase. It has a plasma halflife of 7 minutes and high fibrin specificity. Despite the favorable results of $r$-prourokinase in the Prolyse in Acute Cerebral Thromboembolism I and II trials, ${ }^{20,21}$ the FDA did not approve its use in stroke IAT.

Third-Generation Agents. Reteplase is a structurally modified form of alteplase, with a longer half-life (15-18 minutes). In addition, it does not bind as highly to fibrin; unbound reteplase can thus theoretically better penetrate the clot and potentially improve in vivo fibrinolytic activity. Qureshi et al ${ }^{17}$ reported the use of low-dose IA reteplase ( $\leq 4 \mathrm{U})$ in conjunction with mechanical thrombolysis. Thrombolysis in myocardial infarction (TIMI) 2-3 recanalization was achieved in $16 / 19$ patients, with no sICHs. Tenecteplase is another modified form of rtPA with a longer half-life (17 minutes), greater fibrin specificity, and greater resistance to plasminogen activator inhibitor-1. Pilot clinical trial data of IV tenecteplase in acute ischemic stroke suggest that the drug is safe and promising. $^{22}$

New-Generation Agents. Desmoteplase is a genetically engineered version of the clot-dissolving factor found in the saliva of the vampire bat Desmodus rotundus. This drug is more potent and more selective for fibrin-bound plasminogen than any other known plasminogen activator. Unlike tissue plasminogen activator (tPA), desmoteplase is not activated by fibrinogen or $\beta$-amyloid proteins, factors that may exacerbate the risk for ICH. Moreover, desmoteplase inhibits tPA-induced potentiation of excitotoxic injury. The effect of IV administration of desmoteplase 3-9 hours after symptom onset in patients with stroke who present with mismatch on MR imaging or CT perfusion was systematically investigated in the Desmoteplase in Acute Ischemic Stroke (DIAS), Dose Escalation of Desmoteplase for Acute Ischemic Stroke (DEDAS), and DIAS-II trials and has demonstrated a good safety profile. ${ }^{23-25}$ These studies were notable for their reliance on newer advanced imaging algorithms to plan IA therapy. A new trial (DIAS-III) is planned.

No direct-comparison trials have been reported between the different thrombolytic agents in acute ischemic stroke. In a retrospective review of the results for acute-stroke IAT performed at our center, we found significantly higher rates of recanalization and good clinical outcome in the era in which IA urokinase was used versus the era in which urokinase was not available and IAT with rtPA was the primary treatment. ${ }^{26}$ Conversely, in another retrospective study, Eckert et $\mathrm{al}^{27}$ found no major difference between the recanalization rates of urokinase and rtPA.

Alternatives to Plasminogen Activation: Other Thrombolytics. Thrombolytics that are currently on the market are plasminogen activators, making their successful use reliant, at least in part, on the amount of plasminogen in the thrombus. New drugs that do not depend on the availably of plasminogen are being evaluated for stroke therapy.

Direct Fibrinolytics. V10153 (Vernalis, Winnersh, UK) is a recombinant variant of human plasminogen, which has been genetically modified to be activated to plasmin by thrombin rather than by endogenous plasminogen activator enzymes, such as tissue-type plasminogen activator (tPA). Because thrombin activity is primarily localized at the site of new thrombus formation, administration of V10153 results in the selective production of plasmin at the site of newly formed clot. Consequently, thrombus dissolution may be achieved without systemic plasmin generation, which should result in a reduced risk of hemorrhage. The relatively long plasma halflife (3-4 hours) of V10153 allows bolus administration, and persistence in the circulation may help prevent early vascular reocclusion. The V10153 Acute Stroke Thrombolysis Trial (VASTT) was a phase II dose-escalation multicenter study of IV V10153 in patients with stroke (National Institutes of Health Stroke Scale [NIHSS] score, $>5$ to $\leq 20$; Alberta Stroke Program Early CT Score (ASPECTS), $\geq 5$ ) within 3-9 hours after stroke onset. Preliminary analysis has shown that of the 40 patients enrolled in the first 3 dose groups $(1,2.5$, and 5 $\mathrm{mg} / \mathrm{Kg}), 16(40 \%)$ achieved an mRS score of $\leq 2$ at 90 days. The trial has been halted because 3 of the 9 patients in the 7.5-mg/Kg group developed significant hemorrhagic complications. Further studies with a dose of $5 \mathrm{mg} / \mathrm{Kg}$ are planned.

Microplasmin (ThromboGenics, Heverlee, Belgium) is a truncated form of plasmin that is more resistant to the effects of antiplasmin. In a rabbit stroke model, IV microplasmin infusion resulted in a high rate of clot lysis without increasing the rate of ICH. In addition, there was significant improvement in the behavioral rating scores, suggesting a neuroprotective effect. ${ }^{28}$ The Microplasmin in Treatment of Ischemic Stroke-IntraVenous (MITI-IV) trial, a phase II multicenter randomized double-blinded placebo-controlled ascendingdose clinical trial, evaluated the safety and preliminary efficacy of IV microplasmin in 40 patients treated 4-12 hours after stroke onset. There was no evidence of increased bleeding risk with microplasmin. Reperfusion occurred in $25 \%$ of patients treated with microplasmin versus $10 \%$ of placebo-treated patients.

Alfimeprase (Nuvelo, San Carlos, Calif) is a recombinant 
truncated form of fibrolase, a fibrinolytic zinc metalloproteinase isolated from the venom of the southern copperhead snake. It degrades fibrin directly and achieves thrombolysis independent of plasmin formation. Alfimeprase is rapidly inactivated by $\alpha-2$ macroglobulin as it moves away from the site of delivery into blood circulation. Thus, its thrombolytic activity appears to be localized to the site of delivery. These properties should theoretically result in faster recanalization and lower hemorrhagic conversion risk. The initial data on the safety and efficacy of alfimeprase appeared promising, ${ }^{29}$ but subsequent phase III trials of the drug in peripheral arterial disease and catheter obstruction failed to meet their primary and key secondary end points of revascularization. A phase II multicenter open-label dose-escalation study of alfimeprase in the treatment of acute ischemic stroke (CARNEROS-1) within 3-9 hours of stroke onset is planned.

Defibrinogenating/Fibrinogenolytic Agents. Ancrod (Viprinex; Neurobiological Technologies, Emeryville, Calif) is the purified fraction of the Malayan pit viper venom. It acts by directly cleaving and inactivating fibrinogen and thus indirectly promoting anticoagulation. The reduction in the blood levels of fibrinogen also leads to a reduced blood viscosity, which may improve blood flow to the affected areas of the brain. In addition, ancrod promotes an indirect activation of the plasminogen-plasmin pathway. In the Stroke Treatment with Ancrod Trial, 500 patients with stroke presenting within 3 hours of symptom onset were randomized to receive ancrod $(n=248)$ or a placebo $(n=252)$. Good outcome (Barthel Index, $\geq 95-100$ at 3 months) was achieved in $42.21 \%$ and $34.4 \%$ of the patients, respectively $(P=.04)$. There was no significant difference in mortality, but a trend toward more sICH with ancrod $(5.2 \%$ versus $2 \% ; P=.06) .{ }^{30}$ The ASP-II trial is currently enrolling patients with an NIHSS score between 5 and 25 who presented within 6 hours of stroke onset for treatment with ancrod or a placebo.

\section{Adjunctive Therapy}

Fibrinolytic agents have prothrombotic properties as well. The plasmin generated by thrombolysis leads to the production of thrombin, which is a potent platelet activator and converts fibrinogen to fibrin. Indeed, studies have shown early reocclusion in as many as $17 \%$ of the patients treated with IAT $^{31}$ and $34 \%$ of the patients treated with IV rtPA. ${ }^{32}$ Therefore, a strong rationale exists for the adjuvant use of antithrombotic agents.

Systemic anticoagulation with IV heparin during the periprocedural phase of IAT has several potential advantages, including augmentation of the thrombolytic effect, ${ }^{20}$ prevention of acute reocclusion, and reduction in the risk of catheterrelated embolism. However, these benefits must be weighed against the potentially increased risk of $\mathrm{ICH}$ when heparin is combined with a thrombolytic agent. Argatroban, lepirudin, and bivalirudin are direct thrombin inhibitors. These agents should replace heparin in patients in whom the diagnosis of heparin-induced thrombocytopenia (HIT) type II is confirmed or even suspected. HIT type II is an immune-mediated disorder characterized by the formation of antibodies against the heparin-platelet factor 4 complex, resulting in thrombocytopenia, platelet aggregation, and the potential for arterial and venous thrombosis. The possibility of HIT type II should be raised in patients who demonstrate a platelet count drop to
$<100,000$ or by $>50 \%$ from baseline, in the setting of heparin therapy (usually 5-12 days after initial exposure). Unexplained thrombotic events should also evoke this diagnosis, even in the setting of a normal platelet count. Impaired renal function must be taken into account when selecting the appropriate agent; argatroban is the only direct thrombin inhibitor that is hepatically cleared.

The use of glycoprotein (GP) IIb/IIIa antagonists, such as ReoPro (abciximab), Integrilin (eptifibatide), or Aggrastat (tirofiban) in ischemic stroke remains investigational. No cases of major ICH were seen in a pilot randomized double-blind placebo-controlled study in which 54 patients presenting within 24 hours after ischemic stroke onset were randomly allocated to receive escalating doses of abciximab. ${ }^{33}$ The CLEAR trial subsequently evaluated the combination of lowdose IV rtPA and eptifibatide in patients with NIHSS scores of $>5$ who presented within 3 hours from stroke onset. The study enrolled a total of 94 subjects, with 69 patients receiving the combination therapy and 25 patients receiving standard rtPA therapy. There was $1(1.4 \%) \mathrm{sICH}$ in the combination group and $2(8.0 \%)$ in the standard treatment group $(P=.17)$. There was a nonsignificant trend toward increased efficacy with the standard-dose rtPA treatment arm. The combination of eptifibatide and reduced-dose rtPA was judged safe enough for consideration of further dose-ranging trials in acute ischemic stroke. ${ }^{34}$ ROSIE is another NIH-sponsored phase II trial that is evaluating the use of IV reteplase in combination with abciximab for the treatment of MR imaging - selected patients with stroke within 3-24 hours from onset. Preliminary analysis of the first 21 patients enrolled has revealed no sICH or major hemorrhage. Conversely, the AbESTT II trial, a phase III multicenter randomized double-blind placebo-controlled study evaluating the safety and efficacy of abciximab in acute ischemic stroke treated within 6 hours after stroke onset or within 3 hours of awakening with stroke symptoms, was stopped early due to high rates of sICH or fatal ICH in the abciximabtreated patients $(5.5 \%$ versus $0.5 \%, P=.002) .{ }^{35}$

The data for the use of GP IIb/IIIa inhibitors in conjunction with IAT are even more scant and are limited to case reports. ${ }^{36-41}$ Deshmukh et $\mathrm{al}^{38}$ reported 21 patients with large-vessel occlusion refractory to IAT with rtPA who were treated with IV and/or IA abciximab, eptifibatide, or tirofiban. Twelve patients received IV rtPA and 18 underwent balloon angioplasty. Complete or partial recanalization was achieved in 17 of 21 patients. Three patients (14\%) had asymptomatic ICH, but there were no cases of sICH. Mangiafico et $\mathrm{al}^{41}$ described 21 patients with stroke treated with IV tirofiban and heparin followed by IA urokinase. Nineteen of these patients also underwent balloon angioplasty. TIMI 2-3 flow was achieved in 17 of 21 patients. ICH occurred in 5 of 21 patients ( $3 \mathrm{sICH}$ and 2 subarachnoid hemorrhages [SAHs]) and was fatal in 3 patients. Qureshi et $\mathrm{al}^{40}$ described the use of IA reteplase and IV abciximab on 20 patients with stroke. There was $1 \mathrm{sICH}$. Partial or complete recanalization occurred in 13 of 20 patients. Conversely, the use of abciximab was predictive of asymptomatic SAH $(\mathrm{OR}, 19.2)$ in 9 patients who received this drug as a study protocol violation in the Multi MERCI Part 1 trial. $^{42}$ 


\section{IA Mechanical Approaches in Acute Ischemic Stroke}

Mechanical strategies have several advantages over pharmacologic thrombolysis and may be used as primary or adjunctive strategies. First, they lessen and may even preclude the use of chemical thrombolytics, in this manner very likely reducing the risk of ICH. Second, by avoiding the use of chemical thrombolytics, it is possible to extend the treatment window beyond the limit of $6-8$ hours. Third, mechanically fragmenting a clot increases the surface area accessible to fibrinolytic agents and allows inflow of fresh plasminogen, which, in turn, may increase the speed of thrombolysis. Finally, clot-retrieval devices may provide faster recanalization and may be more efficient at coping with material resistant to enzymatic degradation, including excessive cross-linking in mature embolic clots and emboli composed of cholesterol, calcium, or other debris from atherosclerotic lesions. As such, mechanical approaches with little or no thrombolytic agent have emerged as a key option for patients who have either a contraindication to pharmacologic thrombolysis, such as recent surgery or abnormal hemostasis, ${ }^{43}$ or are late in their presentation. ${ }^{44,45}$ Parenthetically, adjunctive endovascular treatment may be essential for the accomplishment of successful thrombolysis, for example, through recanalization of a proximal occlusive lesion. ${ }^{31,46,47}$ The disadvantages of the mechanical approaches include the technical difficulty of navigating mechanical devices into the intracranial circulation, excessive trauma to the vasculature (potentially leading to vasospasm, vessel dissection, perforation, or rupture), and fragmented thrombus causing distal embolization into previously unaffected territories. Nevertheless, the advantages of mechanical stroke therapy appear to significantly outweigh its disadvantages and risks.

Endovascular Thrombectomy. Endovascular thrombectomy or thrombus retrieval has the advantage of providing rapid flow restoration with a potentially lower likelihood of clot fragmentation and distal embolism when compared with other endovascular techniques. The devices differ with regard to where they apply force on the thrombus, taking either a proximal approach with aspiration or "grasper" devices or a distal approach with basketlike or snarelike devices. A study comparing the effectiveness of these 2 approaches (Vasco35 versus the Catch device [both by Balt Extrusion, Montmorency, France]) in a swine stroke model demonstrated that the proximal device allowed fast repeated application with a low risk of thromboembolic events (3\% versus $26 \%$; OR, 11.3 ; 95\% CI, 1.35-101.6) and vasospasm but a significantly lower success rate in retrieving thrombus than the distal device (39.4\% versus $82.6 \%$; OR, 7.3 ; $95 \% \mathrm{CI}, 2.0-26.4$ ). The rate of embolic events with the distal device could be significantly reduced by using proximal balloon occlusion. ${ }^{48}$ Balloon occlusion with aspiration to promote flow reversal also facilitates clot extraction. ${ }^{49}$

The Merci retriever (Concentric Medical, Mountain View, Calif) is a flexible nitinol wire with coil loops that is used in conjunction with a microcatheter and an $8 \mathrm{~F}$ or $9 \mathrm{~F}$ balloonguided catheter (Fig 2). In August 2004, the FDA approved this system for the indication of intracranial clot retrieval in patients with acute ischemic strokes. ${ }^{44}$ It is estimated that $>9000$ patients have been treated to date with this device. In the first-generation devices (X5 and $\mathrm{X} 6$ ), the nitinol wire was shaped in helical tapering coil loops. The second-generation devices (L4, L5, and L6) differ from the $\mathrm{X}$ devices by the inclusion of a system of arcading filaments attached to a nontapering helical nitinol coil, which has a $90^{\circ}$ angle in relation to the proximal wire component. The third-generation devices $(\mathrm{V}$ series) have variable pitch loops under a linear configuration with attached filaments. The retriever device is deployed through a $2.4 \mathrm{~F}$ microcatheter $(14 \mathrm{X}$ or $18 \mathrm{~L})$. The recent addition of a $4.3 \mathrm{~F}$ distal access catheter has provided additional coaxial support to the system, resulting in improved deliverability with the potential for simultaneous thromboaspiration as well. The Merci embolectomy system has been systematically studied in the MERCI and Multi MERCI trials, which are discussed in Part 2 of this review. ${ }^{44,45}$

The Neuronet device (Guidant, Santa Clara, Calif) is a microguidewire-based laser-cut nitinol basket open proximally with the crisscrossing basket portion tapering to a shapable platinum-tipped wire. This device has been successfully used to retrieve intracranial clots ${ }^{49-51}$ and was prospectively evaluated in a small European trial (Neuronet Evaluation in Embolic stroke Disease). The Catch device is a distally closed self-expanding nitinol cage that has also been used for thrombectomy with promising results. ${ }^{52} \mathrm{~A}$ comparison between the Merci and the Catch devices in an animal model has demonstrated superiority of the Merci retriever, which resulted in higher rates of overall recanalization (90\% versus $70 \%)$, higher chances of recanalization at the first attempt, and a lower rate of thrombus fragmentation/distal embolization. ${ }^{53}$

The Phenox Clot Retriever (phenox, Bochum, Germany) consists of a highly flexible nitinol/platinum-alloy compound core wire surrounded by an attenuated palisade of perpendicularly oriented stiff polyamide microfilaments trimmed in a conical shape, which have an increasing diameter distally and are resistant to unraveling (Fig 3 ). The device is molded to the body of a 0.010 -inch microguidewire and is available in 3 sizes ranging from 3 to $1 \mathrm{~mm}$ proximally and from 5 to $2 \mathrm{~mm}$ distally. It is introduced into the target vessel through a 0.021 or 0.027 -inch microcatheter deployed distal to the thrombus and slowly pulled back under continuous aspiration via the guiding catheter. The smallest version is capable of recanalizing vessel diameters well below $2 \mathrm{~mm}$ such as the distal MCA branches. ${ }^{54}$ This device became available for the treatment of patients with acute ischemic stroke in Europe in October 2006.

A second generation of the device (Phenox Clot Retriever CAGE), which incorporates a nitinol cage into the previous design, has more recently become available for the treatment of thrombi with firmer consistency. Liebig et al ${ }^{55}$ recently reported 48 Phenox treatments in 45 patients with stroke and occlusions involving the terminal/bifurcation ICA $(n=13)$, MCA $(n=18)$, vertebrobasilar system $(n=13)$, or ACA/ posterior cerebral artery (PCA) $(n=4)$. TIMI $2-3$ recanalization was achieved in 27 of 48 treatments (56.3\%). In 3 failed attempts, the device and/or microcatheter could not be deployed. In 11 of these treatments, the target-vessel diameter was $\leq 2 \mathrm{~mm}$. There was no device-related morbidity and mortality. ${ }^{55}$ The Attractor-18 device (Target Therapeutics, Fremont, Calif) is another fiber-based retriever device that has been successfully used to recanalize an occluded superior division branch of the left MCA refractory to IA thrombolytic treatment. $^{56}$ 

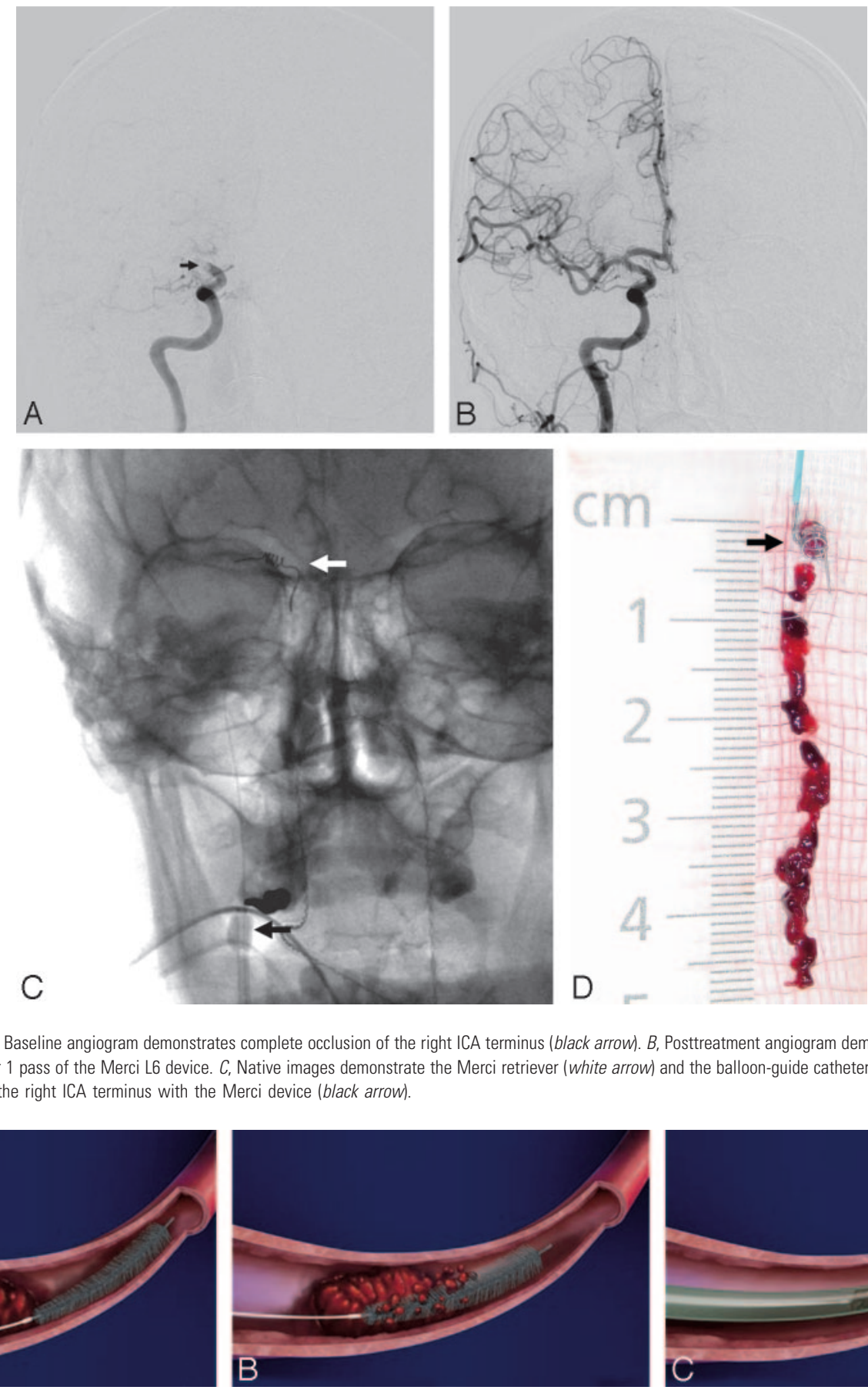

Fig 2. The Merci retriever. $A$, Baseline angiogram demonstrates complete occlusion of the right ICA terminus (black arrow). B, Posttreatment angiogram demonstrates complete reperfusion of the right ICA territory after 1 pass of the Merci L6 device. C, Native images demonstrate the Merci retriever (white arrow) and the balloon-guide catheter (inflated balloon, black arrow). $D$, Thrombus retrieved from the right ICA terminus with the Merci device (black arrow).
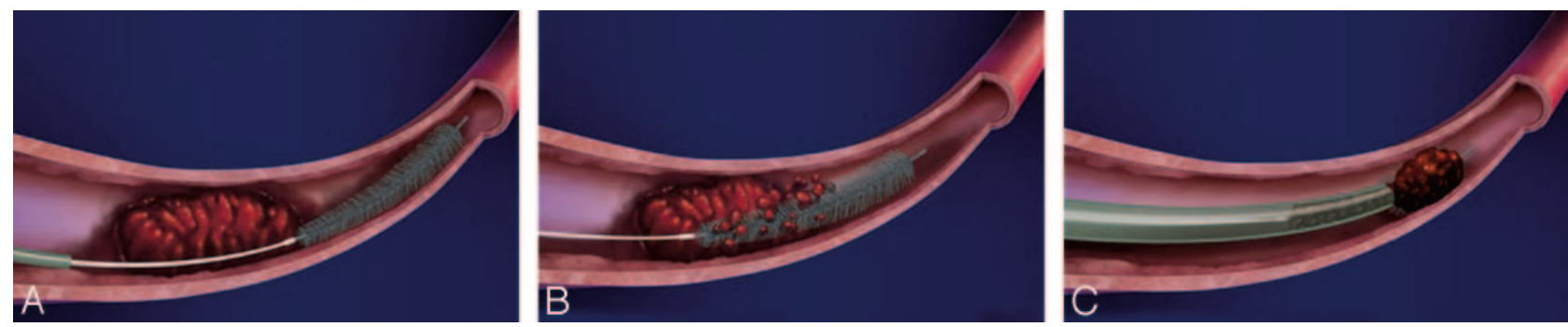

Fig 3. $A-C$, The Phenox retriever is deployed by withdrawing its microcatheter. The device is then slowly withdrawn under continuous blood aspiration through the guiding catheter.

The Alligator Retrieval Device (Chestnut Medical Technologies, Menlo Park, Calif) is a retriever with 4 small grasping jaws attached to the tip of a flexible wire designed to be used in conjunction with a 0.21 -inch microcatheter. ${ }^{57}$ This device has been used to treat 6 patients with intracranial clots (predominantly MCA), resulting in rapid clot removal and clinical improvement in all patients. Two of the 6 patients experienced failure of another clot retrieval device, and 3 patients required no systemic thrombolytics. ${ }^{58}$ The In-Time Retriever (Boston Scientific, Natick, Mass) has 4-6 wire loops and tends to bow when opened but has no specific opening to capture the embolus. This device has been successfully used in a case of MCA occlusion resistant to thrombolytics and balloon angioplasty ${ }^{59}$ and in cases of basilar occlusion. ${ }^{51}$ The TriSpan (Boston Scientific), a neck bridge device consisting of 3 nitinol loops originally designed to treat wide-neck aneurysms, has also been used to treat basilar occlusions. ${ }^{51}$ The EnSnare device (InterV, Gainesville, Fla) has a tulip-shaped 3-loop design which opens distally. Like many of the aforementioned devices, the EnSnare is currently approved for foreign-body removal/coil retrieval. At this point, it has not yet been reported for embolectomy in stroke treatment.

In a recent study comparing the performance of 5 different embolectomy systems by using an in vitro pulsatile flow 

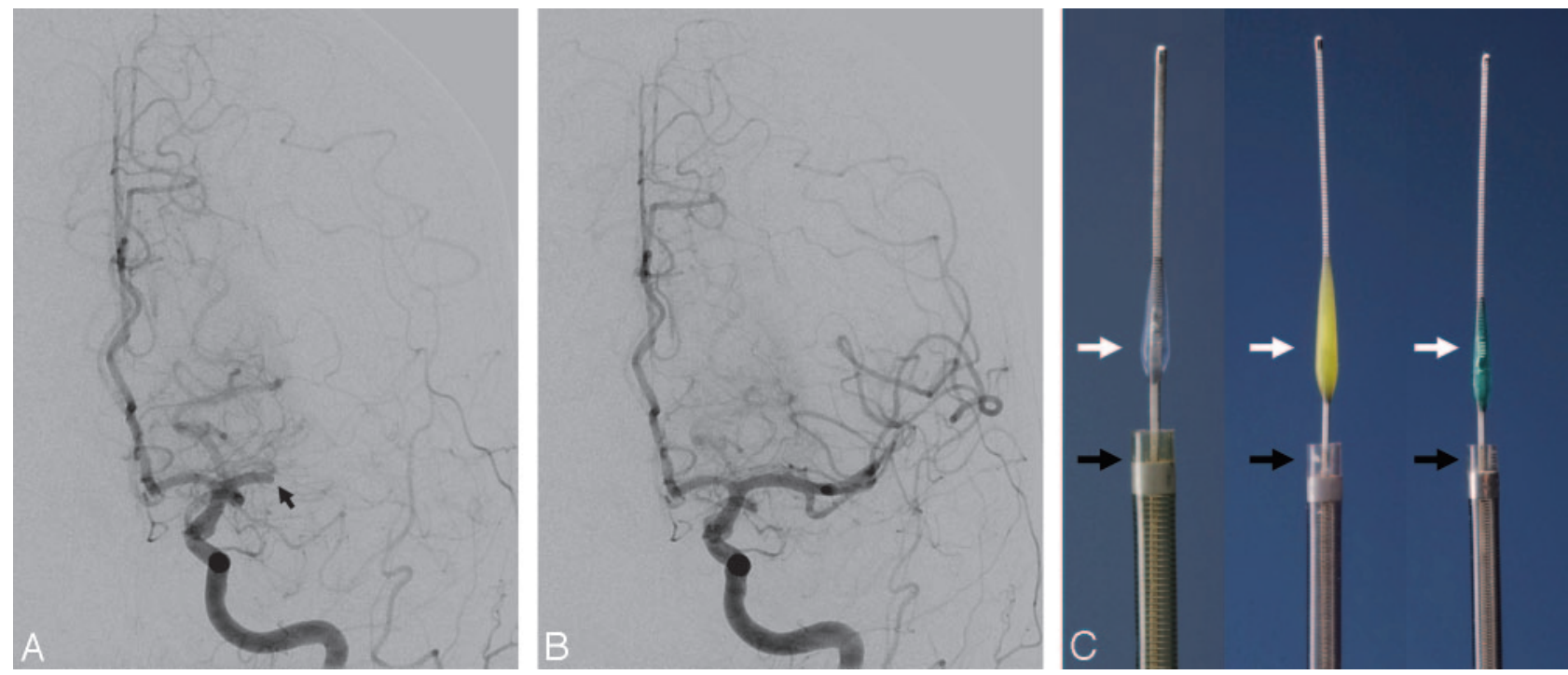

Fig 4. The Penumbra System. $A$, Baseline angiogram demonstrates complete occlusion of the proximal M1 segment left MCA (black arrow). $B$, Posttreatment angiogram demonstrates near-complete reperfusion of the left MCA territory after thromboaspiration with the Penumbra device. $C$, The device is available in 3 different sizes aimed to treat different vessel diameters. Thromboaspiration is achieved by connecting the microcatheter (black arrows) to an aspiration pump. The "separator" (white arrows) is then advanced in and out of the microcatheter to "unclog" any obstructive thrombus.

model, the Merci, Catch, and Phenox retrievers were equally able to mobilize and remove most thrombi, whereas the InTime and Attractor devices achieved only partial thrombus removal at best and with considerable difficulty during initial thrombus penetration and placement of the device. All devices produced micro- and macrofragments during thrombus penetration and retrieval. The Phenox retriever had a superior performance in terms of preventing distal embolization because it was able to capture most of these clot fragments. ${ }^{60}$ This study needs to be interpreted in the context of its oversimplified methodology, which focused on the interaction between the thrombi and the devices but disregarded several other factors that are relevant to mechanical thrombectomy in humans. These include the interactions between the retriever devices and the vessel wall; the thrombus and the vessel wall; and the occurrence of endogenous thrombolysis, additional thrombosis, and vasospasm.

Endovascular Thromboaspiration. Suction thrombectomy or thromboaspiration through either a microcatheter $^{61,62}$ or a guiding catheter ${ }^{63}$ may be an option for a fresh nonadhesive clot. As discussed above, aspiration devices have the advantage of causing fewer embolic events and vasospasm; however, the often more complex design of these devices may make them more difficult to navigate into the intracranial circulation.

The AngioJet system (Possis Medical, Minneapolis, Minn) is a rheolytic thrombectomy device that uses high-pressure saline jets to create a distal Venturi suction, which gently agitates the clot face. The generated clot fragments are then sucked into the access catheter. A 5F AngioJet catheter was used to treat successfully 3 patients who presented with acute stroke in the setting of ICA occlusion. Patency of the carotid artery was re-established in 2 patients. In the third patient, the device was able to create a channel through the column of thrombus, allowing intracranial access. ${ }^{64}$ The NeuroJet (Possis Medical) is a smaller single-channel device specifically developed to be used in the intracranial circulation. Unfortu- nately, issues with vessel dissection and an inability to navigate through the carotid siphon were noted in a pilot study for acute ischemic stroke, and the trial was discontinued. ${ }^{50,65}$ Other vortex-aspiration devices have been developed for the extracerebral circulation, by using high-pressure streams to generate Venturi forces that physically fragment, draw in, and aspirate thrombi, including the Oasis Thrombectomy Catheter System (Boston Scientific), the Amplatz Thrombectomy Device (Microvena, White Bear Lake, Minn), and the Hydrolyzer (Cordis Endovascular, Warren, NJ). ${ }^{65}$ The duration of usage of these devices is typically limited by production of hemolysis.

The Penumbra System (Penumbra, Alameda, Calif) originally included 2 different revascularization options: 1) thrombus debulking and aspiration with a reperfusion catheter that aspirates the clot while a separator device fragments it and prevents obstruction of the catheter, and 2) direct thrombus extraction with a ring retriever while a balloon-guided catheter is used to temporarily arrest flow. This system was initially tested in a pilot trial in Europe, where 23 subjects at 6 international centers were enrolled with 21 vessel occlusions (7 ICAs, 5 MCAs, 9 basilar arteries) treated in 20 patients (mean NIHSS score, $21 \pm 8$ ) up to 8 hours after symptom onset. Three enrolled subjects were not treated due to vessel tortuosity, resulting in an access rate of $87 \%(20 / 23)$. Recanalization before IA lysis was achieved in all treated cases (48\% TIMI 2; 52\% TIMI 3). Six patients were refractory to IV rtPA therapy, and 9 received postdevice IA rtPA. Good outcome at 30 days (defined as an mRS score of $\leq 2$ or NIHSS 4 -point improvement) was demonstrated in $45 \%$ of the patients. The mortality rate was $45 \%$. There were no device-related deaths. There were 8 cases of $\mathrm{ICH}$, of which 2 were symptomatic. Among these $8 \mathrm{ICHs}$, only 1 was thought to be device-related (asymptomatic SAH). The use of adjunctive IA thrombolytic therapy was associated with a higher incidence of hemorrhage. ${ }^{66}$ The results of a subsequent prospective single-arm multicenter trial (Penumbra Stroke Trial) conducted in the United States and Europe led to 

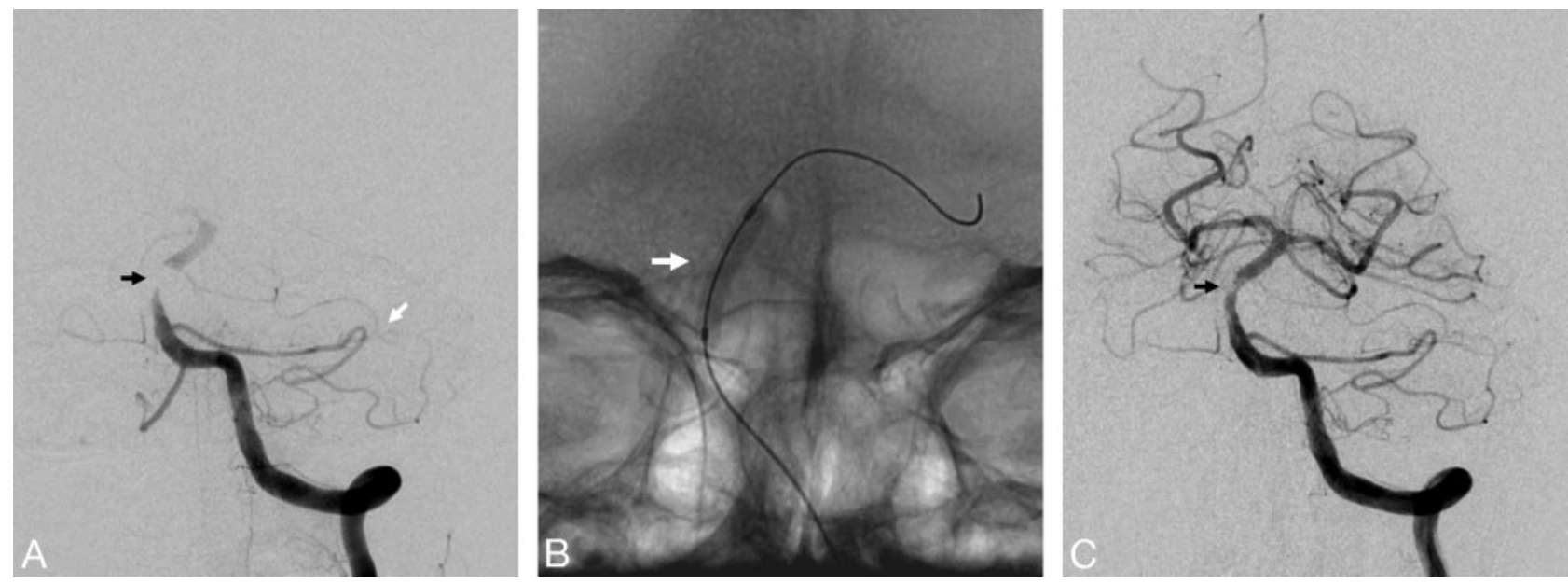

Fig 5. Balloon angioplasty for treatment of atherosclerotic occlusion. $A$, Baseline angiogram demonstrates complete occlusion of the midsegment of the basilar artery (black arrow). Note the PICA - anterior inferior cerebellar artery (AICA) collaterals (white arrow) with reconstitution of flow at the distal basilar artery. $B$, Native image demonstrates an inflated Gateway PTA balloon catheter (Boston Scientific) (white arrow) at the level of the occlusive lesion. $C$, Posttreatment angiogram demonstrates complete reperfusion of the basilar territory with only mild residual stenosis (black arrow).

the FDA approval of the thrombus-aspiration device for clot removal in acute patients with stroke in January 2008 (Fig 4). The Penumbra Stroke Trial is discussed in Part 2 of this review.

The F.A.S.T. Funnel Catheter (Genesis Medical Interventional, Redwood City, Calif) is currently indicated for the removal of thromboembolic material from the peripheral vasculature. This device uses a unique focused aspiration approach via a catheter that provides temporary distal vascular occlusion through the deployment of a funnel-shaped occluder. A smaller platform for use in the cerebrovasculature is under development.

Mechanical Thrombus Disruption. There are several techniques available for mechanical clot disruption. The most common is probing the thrombus with a microguidewire. This technique appears to be useful in facilitating chemical thrombolysis. ${ }^{15}$ Alternatively, a snare (eg, Amplatz gooseneck microsnare, Microvena) can be used for multiple passes through the occlusion to disrupt the thrombus. ${ }^{17,51} \mathrm{~A}$ snare can also be used for clot retrieval, mostly in situations in which the clot has a firm consistency or contains solid material. ${ }^{67}$

Many studies have shown the feasibility and high efficacy of percutaneous transluminal angioplasty (PTA) in acute stroke. ${ }^{41,68-70}$ Nakano et $\mathrm{al}^{69}$ performed a retrospective comparison of 34 patients with acute MCA trunk occlusions who were treated with direct PTA (with subsequent thrombolytic therapy in 21 cases) versus 36 similar patients who were treated with thrombolytic therapy alone. Partial or complete recanalization was achieved in $91.2 \%$ versus $63.9 \%$, sICH was seen in $2.9 \%$ versus $19.4 \%$, and good outcome (mRS score, $\leq 2$ ) occurred in $73.5 \%$ versus $50 \%$ of the patients, respectively. Nogueira et $\mathrm{al}^{39}$ reported the use of low-pressure balloon angioplasty (HyperGlide, ev3, Irvine, Calif) with adjuvant low-dose eptifibatide and/or thrombolytics in 12 consecutive patients. Thrombolysis in Cerebral Ischemia (TICI) 2-3 recanalization was achieved in $11 / 12$ patients $(91.6 \%)$. The only periprocedural complication was a small posterior inferior cerebellar artery (PICA) stroke due to distal embolism. There were no symptomatic intracerebral hemorrhages. Five patients achieved good outcomes (mRS score, $\leq 2) .{ }^{39}$
PTA may be particularly useful in cases of atherothrombotic disease (Fig 5), in which the residual stenosis may reduce flow sufficiently to lead to rethrombosis. ${ }^{31}$ Given the risks of procedural complications such as vessel rupture and distal embolization, this technique is generally reserved as salvage therapy for patients whose flow cannot be restored by more conservative methods. However, this technique has likely become safer with the use of low-pressure more complaint balloons as described above. ${ }^{39,41}$

Two devices that use different laser technologies have been used to disrupt intracranial clots. The EPAR (Endovasix, Belmont, Calif) is a mechanical clot-fragmentation device based on laser technology. However, the emulsification of the thrombus is a mechanical thrombolysis and not a direct laserinduced ablation. The photonic energy is converted to acoustic energy at the fiberoptic tip through creation of microcavitation bubbles. In a pilot study in which 34 patients (10 ICAs, 12 MCAs, 1 PCA, and 11 vertebrobasilar occlusions) with a median NIHSS score of 19 were treated with EPAR, the overall intention-to-treat recanalization rate was $41.1 \%$ (14/34). Vessel recanalization occurred in 11 of 18 patients $(61.1 \%)$ in whom complete EPAR treatment was possible. Additional treatment with IA rtPA occurred in 13 patients. One patient had a vessel rupture resulting in fatality. There were 2 sICHs (5.9\%). The overall mortality rate was $38.2 \% .^{71}$ The LaTIS laser device (LaTIS, Minneapolis, Minn) uses the slow injection of contrast material as a "light pipe" to carry the energy from the catheter to the embolus. ${ }^{50}$ The device was evaluated in a safety and feasibility trial at 2 US centers. A preliminary account reported that the device could not be deployed to the level of the occlusion in 2 of the first 5 patients, and enrollment stopped at 12 patients. Although the catheter design was changed, an efficacy trial has not been pursued. ${ }^{72}$

Augmented Fibrinolysis. The MicroLysUS infusion catheter (EKOS, Bothell, Wash) is a $2.5 \mathrm{~F}$ single-lumen end-hole design microcatheter with a $2-\mathrm{mm} 2.1-\mathrm{MHz}$ piezoelectric sonography element (average power, $0.21-0.45 \mathrm{~W}$ ) at its distal tip, which creates a microenvironment of ultrasonic vibration to facilitate thrombolysis. This is achieved by a combination of 

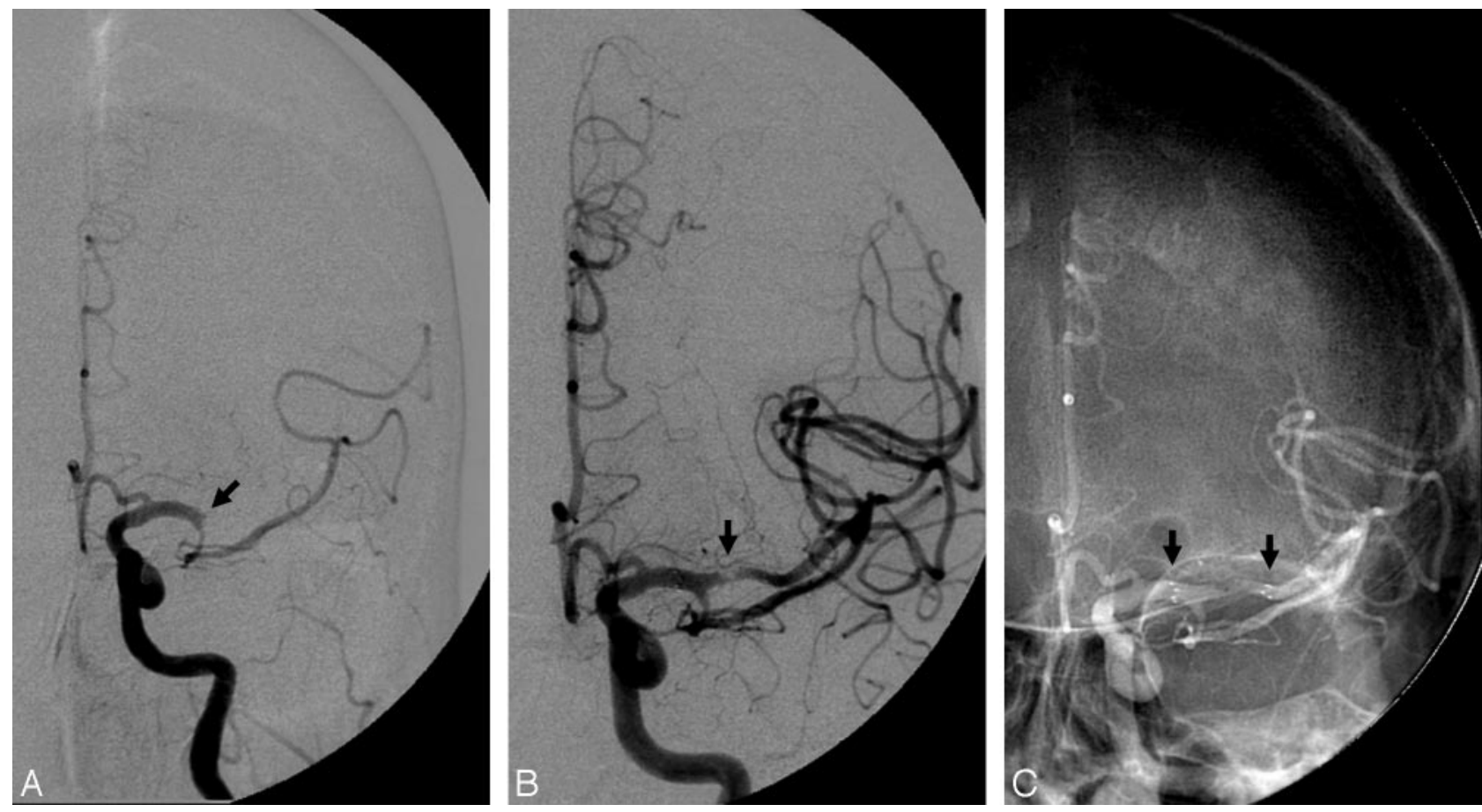

Fig 6. Stent placement for treatment of acute intracranial occlusion. $A$, Baseline angiogram demonstrates complete occlusion at the origin of the superior division of the left MCA (black arrow). B, Posttreatment angiogram demonstrates complete reperfusion of the left MCA superior division territory with only mild residual stenosis (black arrow). $C$, Native image demonstrates the proximal and distal stent markers (black arrows)

a noncavitating sonography, which reversibly separates fibrin strands, and acoustic streaming, which increases fluid permeation, resulting in increased drug-thrombus surface interaction. The net result is enhanced clot dissolution without fragmentation emboli. In a pilot study, in which 10 anteriorcirculation occlusions (5 internal carotid artery-terminus [ICA-T]; 5 MCAs; mean NIHSS score, 18.2) and 4 patients with posterior-circulation occlusions (mean NIHSS score, 18.75) were treated with IA rtPA or reteplase infusion through the EKOS microcatheter and simultaneous sonography transmission for $\leq 60$ minutes, TIMI 2-3 flow was achieved in 8 of $14(57 \%)$ patients in the first hour. Average time to recanalization was 46 minutes. An mRS score of $\leq 2$ was achieved in $43 \%$ of patients at 90 days. Symptomatic ICH occurred in $14 \%$ of patients. The mortality rate was $36 \%$. There were no catheter-related adverse events. ${ }^{73}$ The device was subsequently used in 33 of the 81 patients enrolled in the IMS-II trial. ${ }^{74} \mathrm{~A}$ comparison of final angiographic outcomes between IMS-II subjects treated with the EKOS catheter and IMS-I subjects treated with the standard microcatheter demonstrated grades 2-3 recanalization rates at the specific site of arterial occlusion of 73\% (24/33) in EKOS-treated subjects versus 56\% (33/59) in standard microcatheter-treated subjects $(P=.11){ }^{74}$ This device is being investigated further in the randomized IMS-III trial. Likewise, enhanced fibrinolysis with intravenous rtPA can be achieved with the use of continuous 2-MHz transcranial Doppler sonography (CLOTBUST trial). ${ }^{75}$

The OmniWave Endovascular System (OmniSonics Medical Technologies, Wilmington, Mass) is currently indicated to infuse thrombolytics and remove thrombus in the peripheral vasculature. This system is catheter-based and is delivered over a 0.018 -inch guidewire. It works by directing low-power $(20 \mathrm{kHz})$ ultrasonic energy down a catheter wire that has been tuned to create cavitation bubbles that fracture the fibrin matrix of the thrombus without adversely damaging surrounding vessel walls. Thus, this device has a hybrid mechanism that uses augmented fibrinolysis as well as direct clot disruption to eliminate the occlusive thrombus. As such, it does not necessarily require the use of thrombolysis and provides a theoretic advantage over the EKOS device. In a porcine model of arterial and venous thrombosis, the OmniWave system was found to generate approximately one sixth of the hemolysis seen with the AngioJet system. ${ }^{76}$ OmniSonics has recently signed a licensing and development agreement with Boston Scientific to develop specific devices suited to the neurovasculature.

Thrombus Entrapment. Stent placement of an acutely occluded intracranial vessel may provide fast recanalization by entrapping the thrombus between the stent and the vessel wall (Fig 6). This may be followed by thrombus dissolution via either endogenous or pharmacologic thrombolysis. A study in which 19 patients with acute occlusion at the ICA terminus $(n=8), \mathrm{M} 1 / \mathrm{M} 2(n=7)$, or basilar artery $(n=4)$ were treated with balloon-expandable stents showed a TIMI 2-3 recanalization rate of $79 \%$ and no symptomatic ICHs. ${ }^{77}$ Self-expanding stents (SES) have several potential advantages over balloon-expandable stents in the context of acute stroke. SES are much more flexible and easier to navigate into the intracranial circulation. Indeed, higher rates of recanalization and lower rates of vasospasm and side-branch occlusion were noticed with SES than with balloon-mounted stents in a canine model of vessels acutely occluded with thromboemboli. ${ }^{78}$ As opposed to acute coronary syndromes in which plaque rupture in an underlying atheroma is the most frequent culprit, most cases of acute intracranial vascular occlusions are related to an embolus in the absence of any in situ vascular pathology. Therefore, balloon angioplasty with high-pressure balloons 
and balloon-expandable stents are typically not necessary to recanalize the vessel and may only increase the chance of serious complications such as vessel rupture or dissection. Finally, SES cause less endothelial damage and, therefore, may result in lower rates of early reocclusion or late stent stenosis.

A total of 5 intracranial SES are currently available: 1) the Neuroform stent (Boston Scientific), 2) the Enterprise stent (Cordis, Miami Lakes, Fla), 3) the LEO stent (Balt Extrusion, Montmorency, France), 4) the Solitaire/Solo stent (ev3), and 5 ) the Wingspan stent (Boston Scientific). The first 4 devices are currently marketed for stent-assisted coil embolization of wide-neck aneurysms, whereas the Wingspan stent is approved for the treatment of intracranial atherosclerosis disease. Both the Neuroform and the Wingspan stents have an open-cell design, whereas the Enterprise, Leo, and Solitaire/ SOLO stents have a closed-cell design. The closed-cell design allows resheathing of the stent after partial (70\% for Enterprise; $90 \%$ for Leo $)^{79,80}$ or even full deployment (Solitaire/SOLO). ${ }^{81}$

A recent report described the use of SES (Neuroform3 or Wingspan) to treat 18 patients with stroke (19 lesions) presenting with acute focal occlusions involving the MCA-M1 and/or M2 $(n=9)$, ICA-T $(n=7)$, or vertebrobasilar system $(n=3)$. Stent placement was the initial mechanical maneuver in 6 cases, whereas others involved a combination of pharmacologic and/or mechanical maneuvers prestenting, including 10 balloon angioplasties and 9 clot-retrieval attempts. Gp IIb/ IIIa inhibitors were administered in 10 patients intra- or immediately postprocedurally to avoid acute in-stent thrombosis. TICI/TIMI 2-3 revascularization was achieved in 15 of 19 lesions (79\%). There were no intraprocedural complications, but 7 patients had ICH (either intraparenchymal or subarachnoid) on postprocedural CT, 2 of which were fatal. One patient developed early stent rethrombosis. The in-hospital mortality rate was $38.9 \%$ (7/18). Four patients had mRS scores of $\leq 3$ at the 3 -month follow-up. ${ }^{82}$

Another retrospective analysis evaluated the use of the Neuroform $(n=4)$ or Wingspan $(n=5)$ stents in 9 patients with acute stroke with occlusions involving the MCA $(n=6)$, ICA $(n=2)$, or the vertebrobasilar junction $(n=1)$. Successful stent deployment across the clot occurred in 8 of $9(89 \%)$ patients. In 1 patient, a Wingspan stent could not be tracked beyond the MCA/ICA junction and was deployed in the proximal clot. Complete (TICI/TIMI 3) and partial/complete (TICI 2-3) recanalization occurred in $67 \%$ and $89 \%$ of the patients, respectively. There was $1 \mathrm{ICH}(11 \%)$ and 1 acute in-stent thrombosis (successfully treated with abciximab and balloon angioplasty). The mortality rate was 33\% (3/9). All survivors achieved an $\mathrm{mRS}$ score of $\leq 2$. Follow-up angiography was performed in 4 of the 9 patients at a mean of 8 months (range, 2-14 months) and showed no stent restenosis. ${ }^{83}$ Isolated case reports of successful intracranial recanalization with the Neuroform stent have also been reported by other authors. $^{84-86}$

$\operatorname{Jahan}^{87}$ recently presented the preliminary data about the use of the Solitaire/SOLO device as a temporary endovascular bypass and clot retriever in a swine stroke model. Immediate flow restoration following device deployment was achieved in 5 of 6 vessels. Clot retrieval resulting in TIMI 3 flow was achieved in 6 of 6 vessels compared with 2 of 3 vessels treated with the Merci retriever. Histologic evaluation of treated arteries demonstrated that the Solitaire/Solo device compared favorably with the Merci retriever. ${ }^{87}$ SES with higher radial force (eg, Wingspan) will likely play a key role patients with acute stroke related to intracranial atherosclerotic disease. ${ }^{88}$

Stent placement of the proximal cervical vessels may also be required to gain access to the intracranial thrombus with other mechanical devices or catheters. Furthermore, brisk antegrade flow is essential for the maintenance of distal vascular patency, as particularly evident in patients with severe proximal stenoses who commonly develop rethrombosis after vessel recanalization. In a recent series, 23 of 25 patients (92\%) with acute $(n=15)$ or subacute $(n=10)$ cervical ICA occlusions were successfully revascularized with this technique. ${ }^{89}$

Temporary Endovascular Bypass. As discussed above, stents may result in high recanalization rates over a relatively short procedural time. The need for an aggressive antithrombotic regimen after stent implantation remains one of the major limitations to its use in acute stroke. However, the advent of closed-cell stents has allowed resheathing/removal of the stent after recanalization is achieved, moderating the need for dual antiplatelet therapy, which could potentially increase the risk of hemorrhagic conversion of the infarct. In addition, this technique should eliminate the risk of delayed in-stent stenosis. Kelly et $\mathrm{al}^{90}$ recently reported a case in which partial deployment of an Enterprise stent resulted in immediate recanalization of an occluded MCA that was refractory to IV and IA rtPA, IA abciximab, and mechanical manipulation. The unconstrained portion of the stent expanded and acted as a temporary bypass to circumferentially displace and structurally disrupt the occlusive clot while additional abciximab was administered through the guiding catheter. The partially expanded stent was then reconstrained and removed 20 minutes later. ${ }^{90}$ A similar approach can be theoretically applied to other reconstrainable stents such as the Leo or the Solitaire/ Solo. This temporary endovascular bypass technique is the main mechanism for the use of the ReVasc device (ReVasc Technologies, Cleveland, Ohio), an SES-like device recently acquired by Micrus Endovascular (San Jose, Calif).

\section{Alternative Reperfusion Strategies}

The alternative reperfusion strategies consist of nonrecanalization modalities and involve the collateral vasculature as well as retrograde and reversed flow. They can be subcategorized into the following: 1) global reperfusion (flow augmentation or transarterial retrograde reperfusion), and 2) transvenous retrograde reperfusion (flow reversal).

\section{Global Reperfusion or Flow Augmentation}

Global reperfusion or flow augmentation focuses on increasing cerebral blood flow (CBF) to perfuse the tissue bed distal to the occlusive thrombus via leptomeningeal and/or circle of Willis collaterals. The antegrade component of flow augmentation plays a direct role only in occlusions proximal to the circle of Willis, whereas most of the tissue reperfusion seen in cases of distal branch occlusions relies on increased flow to leptomeningeal collaterals with resultant retrograde filling of the occluded vessel down to the level of the occlusive thrombus (transarterial retrograde reperfusion). Of note, these flowaugmentation strategies may potentially lead to better recan- 

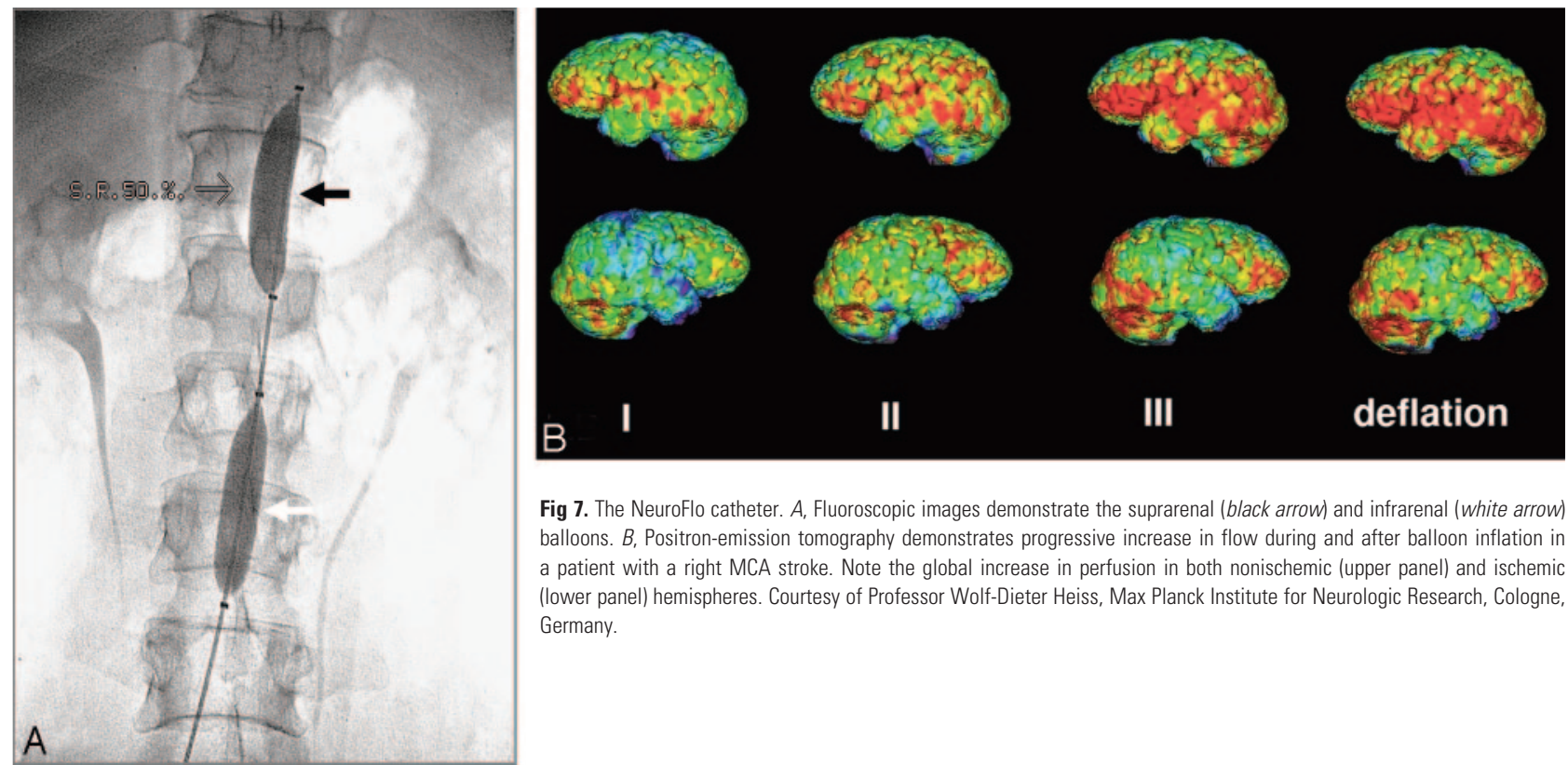

Fig 7. The NeuroFlo catheter. A, Fluoroscopic images demonstrate the suprarenal (black arrow) and infrarenal (white arrow) balloons. $B$, Positron-emission tomography demonstrates progressive increase in flow during and after balloon inflation in a patient with a right MCA stroke. Note the global increase in perfusion in both nonischemic (upper panel) and ischemic (lower panel) hemispheres. Courtesy of Professor Wolf-Dieter Heiss, Max Planck Institute for Neurologic Research, Cologne, Germany.

alization rates when used as an adjunct to antegrade reperfusion treatments. For example, it has been shown that ipsilateral pretreatment $\mathrm{CBF}$ influences vessel recanalization in IAT for MCA occlusion ${ }^{91}$ and that a greater degree of collateral circulation on pretreatment angiography is associated with higher rates of recanalization with the Merci retriever. ${ }^{92}$ In addition, improvement in CBF should result in greater delivery of thrombolytic drugs to the occlusion site, theoretically leading to higher recanalization rates with systemic thrombolysis. Given the lesser degree of complexity involved in collateral perfusion augmentation, these techniques could potentially result in shorter reperfusion times compared with many recanalization therapies.

Flow augmentation can be achieved by either pharmacologic (eg, IV phenylephrine infusion $)^{93}$ or mechanical approaches (eg, the NeuroFlo device). The NeuroFlo device (CoAxia, Maple Grove, Minn) is a dual balloon catheter uniquely designed for partial occlusion $(\sim 70 \%)$ of the aorta above and below the origin of the renal arteries (Fig 7). ${ }^{94}$ This device appears to work through mechanical flow diversion from the high-resistance lower body to the lower resistance cerebral circulation. Although yet uncharacterized, neurohumoral mechanisms are also thought to play a role. In fact, experimental evidence suggests that NeuroFlo increases global cerebral perfusion within minutes of balloon inflation, with little or no increase in mean arterial blood pressure. In a nonstroke porcine model that used isotope-labeled microspheres to measure regional blood flow, partial aortic occlusion with the NeuroFlo catheter resulted in a significant increase in CBF (approximately 30\%-50\%) in all regions of the brain. This was achieved without any significant change in cardiac performance or blood flow in any of the other tissue beds studied, including the renal cortex and medulla. This increase in CBF was maintained until the end of the experiment, 90 minutes after the balloon deflation (M. Hammer, personal communication, November 2008). A recent embolic stroke rat model demonstrated that 1 hour of suprarenal aortic occlusion reduced infarct size from $44.2 \pm 4.9 \%$ of the hemisphere (saline control) to $25 \pm 5.4 \%$. The use of rtPA alone reduced infarct size to $21.4 \pm 4.9 \%$, whereas the combination of rtPA and suprarenal aortic occlusion reduced infarct size to $14 \pm 3.7 \%$. This reduction in final infarct volume was achieved without an increase in hemorrhage risk as measured by total tissue hemoglobin. Perfusion deficits were $4.6 \pm 0.6 \mathrm{~mm}^{2}$ at 2 hours after embolization in the control animals and were significantly decreased to $1.7 \pm 0.6 \mathrm{~mm}^{2}$ by 1 hour of suprarenal aortic occlusion $(P=.003)$ (A. Shuaib, personal communication, November 2008).

The safety profile of the NeuroFlo device has been demonstrated by its use in $>200$ patients with ischemic stroke or cerebral vasospasm, including in patients up to 48 hours poststroke onset. The clinical studies involving this device will be discussed in Part 2 of this review. A new generation of the NeuroFlo catheter that allows distal access to intracranial vasculature is currently being developed. This will provide the ability to perform IA recanalization therapies while promoting flow augmentation through partial aortic obstruction.

\section{Transvenous Retrograde Reperfusion or Flow Reversal}

This experimental treatment technique, transvenous retrograde reperfusion or flow reversal, focuses on reversing the cerebral flow direction from arteries-capillaries-veins to veins-capillaries-arteries.

Partial or Venous Flow Reversal. The first attempt of flow reversal was the retrograde transvenous neuroperfusion (RTN), which used an external pump to harvest arterial blood from the subject's femoral artery and to transport the blood through 2 catheters placed into each of the transverse sinuses near the torcula. The blood was directed retrograde, opposite to normal venous flow, through the central, deep, and superficial sinuses and veins to reach the capillary bed. A baboon study in which RTN was started 1 hour after MCA occlusion in treated animals showed significantly improved somatosensory-evoked potentials and combined neurologic scores and a lower infarction volume compared with untreated animals. ${ }^{95}$ An abstract reported the safety and feasibility of RTN treat- 
ment in 6 patients; however, larger clinical trials have not been reported.

Complete Arteriovenous Flow Reversal. The ReviveFlow system (ReviveFlow, Quincy, Mass) is a novel method of cerebral flow reversal in which a balloon guide catheter is placed in the cervical ICAs and jugular veins on 1 or both sides of the neck. The balloons are subsequently inflated, and blood is aspirated via an external pump system from the proximal ICA and infused in the distal internal jugular vein. The end result is total reversal of the cerebral circulation and perfusion of the venous system with arterial blood into the capillary bed, which is now physiologically proximal to the occluded artery. This device is currently undergoing preclinical studies.

\section{Conclusions}

Endovascular stroke therapy continues to evolve, and we would posit, to improve. The therapeutic advances have come from many directions including pharmacologic and mechanical. Novel drugs with innovative mechanisms of action and theoretically improved safety profile are being developed. New recanalization strategies that may further improve what is presently available are being tested. Advanced imaging, though not a focus of this article, provides critical insight into the pathophysiology of stroke. This greater understanding fosters novel alternative approaches to reperfusion that take us beyond the mechanics of rapid revascularization.

In the second installment of this 2-part series, the focus will shift to a discussion of the historically relevant and completed current/ongoing and upcoming trials. Data will be reviewed and a thesis advanced as to the place IA treatment should have in stroke algorithms.

\section{References}

1. Stroke: 1989-recommendations on stroke prevention, diagnosis, and therapy: report of the WHO Task Force on Stroke and other Cerebrovascular Disorders. Stroke 1989;20:1407-31

2. Rosamond W, Flegal K, Furie K, et al. Heart disease and stroke statistics: 2008 update- a report from the American Heart Association Statistics Committee and Stroke Statistics Subcommittee. Circulation 2008;117:e25-146

3. Tissue plasminogen activator for acute ischemic stroke: The National Institute of Neurological Disorders and Stroke rtPA Stroke Study Group. N Engl J Med 1995;333:1581-87

4. Practice advisory: thrombolytic therapy for acute ischemic stroke-summary statement. Report of the Quality Standards Subcommittee of the American Academy of Neurology. Neurology 1996;47:835-39

5. Adams HP Jr, Brott TG, Furlan AJ, et al. Guidelines for thrombolytic therapy for acute stroke: a supplement to the guidelines for the management of patients with acute ischemic stroke-a statement for healthcare professionals from a Special Writing Group of the Stroke Council. American Heart Association. Circulation 1996;94:1167-74

6. Wardlaw JM, Zoppo G, Yamaguchi T, et al. Thrombolysis for acute ischaemic stroke. Cochrane Database Syst Rev 2003:CD000213

7. Hacke W, Donnan G, Fieschi C, et al. Association of outcome with early stroke treatment: pooled analysis of ATLANTIS, ECASS, and NINDS rtPA stroke trials. Lancet 2004;363:768-74

8. Hacke W, Kaste M, Bluhmki E, et al. Thrombolysis with alteplase 3 to 4.5 hours after acute ischemic stroke. $N$ Engl J Med 2008;359:1317-29

9. Wolpert SM, Bruckmann H, Greenlee R, et al. Neuroradiologic evaluation of patients with acute stroke treated with recombinant tissue plasminogen activator: the rtPA Acute Stroke Study Group. AJNR Am J Neuroradiol 1993;14:3-13

10. Caplan LR, Mohr JP, Kistler JP, et al.. Should thrombolytic therapy be the first-line treatment for acute ischemic stroke? Thrombolysis-not a panacea for ischemic stroke. N Engl J Med 1997;337:1309-10, discussion 1313

11. Haley EC Jr, Lewandowski C, Tilley BC. Myths regarding the NINDS rtPA Stroke Trial: setting the record straight. Ann Emerg Med 1997;30:676-82

12. Saver JL. Number needed to treat estimates incorporating effects over the entire range of clinical outcomes: novel derivation method and application to thrombolytic therapy for acute stroke. Arch Neurol 2004;61:1066-70
13. Kleindorfer D, Lindsell CJ, Brass L, et al. National US estimates of recombinant tissue plasminogen activator use: ICD-9 codes substantially underestimate. Stroke 2008;39:924-28. Epub 2008 Jan 31

14. Reeves MJ, Arora S, Broderick JP, et al. Acute stroke care in the US: results from 4 pilot prototypes of the Paul Coverdell National Acute Stroke Registry. Stroke 2005;36:1232-40

15. Barnwell SL, Clark WM, Nguyen TT, et al. Safety and efficacy of delayed intraarterial urokinase therapy with mechanical clot disruption for thromboembolic stroke. AJNR Am J Neuroradiol 1994;15:1817-22

16. Lisboa RC, Jovanovic BD, Alberts MJ. Analysis of the safety and efficacy of intra-arterial thrombolytic therapy in ischemic stroke. Stroke 2002;33: 2866-71

17. Qureshi AI, Siddiqui AM, Suri MF, et al. Aggressive mechanical clot disruption and low-dose intra-arterial third-generation thrombolytic agent for ischemic stroke: a prospective study. Neurosurgery 2002;51:1319-27, discussion $1327-29$

18. Cornu C, Boutitie F, Candelise L, et al. Streptokinase in acute ischemic stroke: an individual patient data meta-analysis-The Thrombolysis in Acute Stroke Pooling Project. Stroke 2000;31:1555-60

19. Kaur J, Zhao Z, Klein GM, et al. The neurotoxicity of tissue plasminogen activator? J Cereb Blood Flow Metab 2004;24:945-63

20. del Zoppo GJ, Higashida RT, Furlan AJ, et al. PROACT: a phase II randomized trial of recombinant pro-urokinase by direct arterial delivery in acute middle cerebral artery stroke-PROACT Investigators. Prolyse in Acute Cerebral Thromboembolism. Stroke 1998;29:4-11

21. Furlan A, Higashida R, Wechsler L, et al. Intra-arterial prourokinase for acute ischemic stroke: The PROACT II study—a randomized controlled trial. Prolyse in Acute Cerebral Thromboembolism. JAMA 1999;282:2003-11

22. Haley EC Jr, Lyden PD, Johnston KC, et al. A pilot dose-escalation safety study of tenecteplase in acute ischemic stroke. Stroke 2005;36:607-12

23. Hacke W, Albers G, Al-Rawi Y, et al. The Desmoteplase in Acute Ischemic Stroke Trial (DIAS): a phase II MRI-based 9-hour window acute stroke thrombolysis trial with intravenous desmoteplase. Stroke 2005;36:66-73. Epub 2004 Nov 29

24. Furlan AJ, Eyding D, Albers GW, et al. Dose Escalation of Desmoteplase for Acute Ischemic Stroke (DEDAS): evidence of safety and efficacy 3 to 9 hours after stroke onset. Stroke 2006;37:1227-31

25. Hacke W. Desmoteplase in Acute Ischemic Stroke Trial-2 (DIAS-2). Abstract presented at: 16th European Stroke Conference; May 29-June 1, 2007; Glasgow, Scotland

26. Hoh BL, Nogueira RG, O’Donnell J, Pryor JC, et al. Intra-arterial thrombolysis for acute stroke: comparison of era using urokinase versus era not using urokinase at a single center. Abstract presented at: Seventh Joint Meeting of the AANS/CNS Section on Cerebrovascular Surgery and the American Society of Interventional and Therapeutic Neuroradiology; February 1-4, 2004; San Diego, Calif

27. Eckert B, Kucinski T, Neumaier-Probst E, et al. Local intra-arterial fibrinolysis in acute hemispheric stroke: effect of occlusion type and fibrinolytic agent on recanalization success and neurological outcome. Cerebrovasc Dis 2003; $15: 258-63$

28. Lapchak PA, Araujo DM, Pakola S, et al. Microplasmin: a novel thrombolytic that improves behavioral outcome after embolic strokes in rabbits. Stroke 2002;33:2279-84

29. Deitcher SR, Toombs CF. Non-clinical and clinical characterization of a nove acting thrombolytic: alfimeprase. Pathophysiol Haemost Thromb 2005;34: 215-20

30. Sherman DG, Atkinson RP, Chippendale T, et al. Intravenous ancrod for treatment of acute ischemic stroke: the STAT study-a randomized controlled trial. Stroke Treatment with Ancrod Trial. JAMA 2000;283:2395-403

31. Qureshi AI, Siddiqui AM, Kim SH, et al. Reocclusion of recanalized arteries during intra-arterial thrombolysis for acute ischemic stroke. AJNR Am J Neuroradiol 2004;25:322-28

32. Alexandrov AV, Grotta JC. Arterial reocclusion in stroke patients treated with intravenous tissue plasminogen activator. Neurology 2002;59:862-67

33. Abciximab in acute ischemic stroke: a randomized, double-blind, placebocontrolled, dose-escalation study-The Abciximab in Ischemic Stroke Investigators. Stroke 2000;31:601-09

34. Pancioli AM, Broderick J, Brott T, for the CLEAR Trial Investigators. The com bined approach to lysis utilizing eptifibatide and rtPA in acute ischemic stroke: the CLEAR stroke trial. Stroke 2008;39:3268-76. Epub 2008 Sep 4

35. Adams HP Jr, Effron MB, Torner J, et al. Emergency administration of abciximab for treatment of patients with acute ischemic stroke: results of an international phase III trial-Abciximab in Emergency Treatment of Stroke Trial (AbESTT-II). Stroke 2008;39:87-99. Epub 2007 Nov 21

36. Eckert B, Koch C, Thomalla G, et al. Acute basilar artery occlusion treated with combined intravenous Abciximab and intra-arterial tissue plasminogen activator: report of 3 cases. Stroke 2002;33:1424-27

37. Lee DH, Jo KD, Kim HG, et al. Local intraarterial urokinase thrombolysis of acute ischemic stroke with or without intravenous abciximab: a pilot study. $J$ Vasc Interv Radiol 2002;13:769-74

38. Deshmukh VR, Fiorella DJ, Albuquerque FC, et al. Intra-arterial thrombolysis 
for acute ischemic stroke: preliminary experience with platelet glycoprotein IIb/IIIa inhibitors as adjunctive therapy. Neurosurgery 2005;56:46-54, discussion 54-55

39. Nogueira RG, Schwamm LH, Buonanno FS, et al. Low-pressure balloon angioplasty with adjuvant pharmacological therapy in patients with acute ischemic stroke caused by intracranial arterial occlusions. Neuroradiology 2008;50: 331-40

40. Qureshi AI, Harris-Lane P, Kirmani JF, et al. Intra-arterial reteplase and intravenous abciximab in patients with acute ischemic stroke: an open-label, doseranging, phase I study. Neurosurgery 2006;59:789-96, discussion 796-97

41. Mangiafico S, Cellerini M, Nencini P, et al. Intravenous glycoprotein IIb/IIIa inhibitor (tirofiban) followed by intra-arterial urokinase and mechanical thrombolysis in stroke. AJNR Am J Neuroradiol 2005;26:2595-601

42. Smith WS. Safety of mechanical thrombectomy and intravenous tissue plasminogen activator in acute ischemic stroke: results of the multi Mechanical Embolus Removal in Cerebral Ischemia (MERCI) trial, part I. AJNR Am J Neuroradiol 2006;27:1177-82

43. Nogueira RG, Smith WS. Safety and efficacy of endovascular thrombectomy in patients with abnormal hemostasis: pooled analysis of the MERCI and Multi MERCI trials. Stroke. 2009;40:516-22. Epub 2008 Dec 18

44. Smith WS, Sung G, Starkman S, et al. Safety and efficacy of mechanical embolectomy in acute ischemic stroke: results of the MERCI trial. Stroke 2005;36:1432-38

45. Smith WS, Sung G, Saver J, et al. Mechanical thrombectomy for acute ischemic stroke: final results of the Multi MERCI trial. Stroke 2008;39:1205-12. Epub 2008 Feb 28

46. Yu W, Binder D, Foster-Barber A, et al. Endovascular embolectomy of acute basilar artery occlusion. Neurology 2003;61:1421-23

47. Ueda T, Hatakeyama T, Kohno K, et al. Endovascular treatment for acute thrombotic occlusion of the middle cerebral artery: local intra-arterial thrombolysis combined with percutaneous transluminal angioplasty. Neuroradiology 1997;39:99-104

48. Gralla J, Schroth G, Remonda L, et al. Mechanical Thrombectomy for Acute Ischemic Stroke: Thrombus-Device Interaction, Efficiency, and Complications In Vivo. Stroke 2006;37:3019-24. Epub 2006 Oct 19

49. Mayer TE, Hamann GF, Brueckmann H. Mechanical extraction of a basilarartery embolus with the use of flow reversal and a microbasket. $N$ Engl J Med 2002;347:769-70

50. Nesbit GM, Luh G, Tien R, et al. New and future endovascular treatment strategies for acute ischemic stroke. J Vasc Interv Radiol 2004;15:S103-10

51. Bergui M, Stura G, Daniele D, et al. Mechanical thrombolysis in ischemic stroke attributable to basilar artery occlusion as first-line treatment. Stroke 2006;37:145-50

52. Chapot R. First experience with the Catch, a new device for cerebral thrombectomy. Intervent Neuroradiol 2005;11(suppl 2):58

53. Brekenfeld C, Schroth G, El-Koussy M, et al. Mechanical thromboembolectomy for acute ischemic stroke: comparison of the catch thrombectomy device and the Merci Retriever in vivo. Stroke 2008;39:1213-19

54. Henkes H JR, Lowens S, Miloslavski E, et al. A device for fast mechanical clot retrieval from intracranial arteries (Phenox clot retriever). Neurocrit Care 2006;5:134-40

55. Liebig T, Reinartz J, Guethe T, et al. Early clinical experiences with a new thrombectomy device for the treatment of ischemic stroke. Stroke 2008;39:608

56. Schumacher HC, Meyers PM, Yavagal DR, et al. Endovascular mechanical thrombectomy of an occluded superior division branch of the left MCA for acute cardioembolic stroke. Cardiovasc Intervent Radiol 2003;26:305-08

57. Henkes H, Lowens S, Preiss H, et al. A new device for endovascular coil retrieval from intracranial vessels: alligator retrieval device. AJNR Am J Neuroradiol 2006;27:327-29

58. Kerber CW, Wanke I, Bernard J Jr, et al. Rapid intracranial clot removal with a new device: the alligator retriever. AJNR Am J Neuroradiol 2007;28:860-63

59. Veznedaroglu E, Levy EI. Endovascular management of acute symptomatic intracranial arterial occlusion. Neurosurgery 2006;59:S242-50

60. Liebig T, Reinartz J, Hannes R, et al. Comparative in vitro study of five mechanical embolectomy systems: effectiveness of clot removal and risk of distal embolization. Neuroradiology 2008;50:43-52

61. Chapot R, Houdart E, Rogopoulos A, et al. Thromboaspiration in the basilar artery: report of two cases. AJNR Am J Neuroradiol 2002;23:282-84

62. Brekenfeld C, Remonda L, Nedeltchev K, et al. Endovascular neuroradiological treatment of acute ischemic stroke: techniques and results in 350 patients. Neurol Res 2005;27(suppl 1):S29-35

63. Lutsep HL, Clark WM, Nesbit GM, et al. Intraarterial suction thrombectomy in acute stroke. AJNR Am J Neuroradiol 2002;23:783-86

64. Bellon RJ, Putman CM, Budzik RF, et al. Rheolytic thrombectomy of the occluded internal carotid artery in the setting of acute ischemic stroke. AJNR Am J Neuroradiol 2001;22:526-30

65. Molina CA, Saver JL. Extending reperfusion therapy for acute ischemic stroke: emerging pharmacological, mechanical, and imaging strategies. Stroke 2005;36:2311-20

66. Bose A, Henkes H, Alfke K, et al. The Penumbra System: a mechanical device for the treatment of acute stroke due to thromboembolism. AJNR Am J Neuroradiol 2008;29:1409-13. Epub 2008 May 22

67. Kerber CW, Barr JD, Berger RM, et al. Snare retrieval of intracranial thrombus in patients with acute stroke. J Vasc Interv Radiol 2002;13:1269-74

68. Ueda T, Sakaki S, Nochide I, et al. Angioplasty after intra-arterial thrombolysis for acute occlusion of intracranial arteries. Stroke 1998;29:2568-74

69. Nakano S, Iseda T, Yoneyama T, et al. Direct percutaneous transluminal angioplasty for acute middle cerebral artery trunk occlusion: an alternative option to intra-arterial thrombolysis. Stroke 2002;33:2872-76

70. Abou-Chebl A, Bajzer CT, Krieger DW, et al. Multimodal therapy for the treatment of severe ischemic stroke combining GP IIb/IIIa antagonists and angioplasty after failure of thrombolysis. Stroke 2005;36:2286-88

71. Berlis A, Lutsep H, Barnwell S, et al. Mechanical thrombolysis in acute ischemic stroke with endovascular photoacoustic recanalization. Stroke 2004;35: 1112-16. Epub 2004 Mar 11

72. Lutsep H. Mechanical thrombolysis in acute stroke: emedicine. November 2 , 2006. Available at: http://emedicine.medscape.com. Accessed December 10, 2008

73. Mahon BR, Nesbit GM, Barnwell SL, et al. North American clinical experience with the EKOS MicroLysUS infusion catheter for the treatment of embolic stroke. AJNR Am J Neuroradiol 2003;24:534-38

74. IMS II Trial Investigators. The Interventional Management of Stroke (IMS) II Study. Stroke 2007;38:2127-35. Epub 2007 May 24

75. Alexandrov AV, Molina CA, Grotta JC, et al. Ultrasound-enhanced systemic thrombolysis for acute ischemic stroke. N Engl J Med 2004;351:2170-78

76. Lang EV, Kulis AM, Villani M, et al. Hemolysis comparison between the OmniSonics OmniWave Endovascular System and the Possis AngioJet in a porcine model. J Vasc Interv Radiol 2008;19:1215-21. Epub 2008 Jun 2

77. Levy EI, Ecker RD, Horowitz MB, et al. Stent-assisted intracranial recanalization for acute stroke: early results. Neurosurgery 2006;58:458-63

78. Levy EI, Sauvageau E, Hanel RA, et al. Self-expanding versus balloon-mounted stents for vessel recanalization following embolic occlusion in the canine model: technical feasibility study. AJNR Am J Neuroradiol 2006;27:2069-72

79. Peluso JP, van Rooij WJ, Sluzewski M, et al. A new self-expandable nitinol stent for the treatment of wide-neck aneurysms: initial clinical experience. $A J N R$ Am J Neuroradiol 2008;29:1405-08

80. Lubicz B, Leclerc X, Levivier M, et al. Retractable self-expandable stent for endovascular treatment of wide-necked intracranial aneurysms: preliminary experience. Neurosurgery 2006;58:451-57

81. Yavuz K, Geyik S, Pamuk AG, et al. Immediate and midterm follow-up results of using an electrodetachable, fully retrievable SOLO stent system in the endovascular coil occlusion of wide-necked cerebral aneurysms. J Neurosurg 2007;107:49-55

82. Levy EI, Mehta R, Gupta R, et al. Self-expanding stents for recanalization of acute cerebrovascular occlusions. AJNR Am J Neuroradiol 2007;28:816-22

83. Zaidat OO, Wolfe T, Hussain SI, et al. Interventional acute ischemic stroke therapy with intracranial self-expanding stent. Stroke 2008;39:2392-95

84. Fitzsimmons BF, Becske T, Nelson PK. Rapid stent-supported revascularization in acute ischemic stroke. AJNR Am J Neuroradiol 2006;27:1132-34

85. Sauvageau E, Levy EI. Self-expanding stent-assisted middle cerebral artery recanalization: technical note. Neuroradiology 2006;48:405-08

86. Dabus G, Nogueira RG. Empty microcatheter technique for the deployment of a self-expanding stent to treat refractory middle cerebral artery occlusion in the setting of severe proximal tortuosity. J Neuroimaging 2008 Apr 3. [Epub ahead of print]

87. Jahan R. A novel, self expanding, fully retractable mechanical thromboembolectomy device for treatment of acute ischemic stroke. Abstract presented at: 5th Annual Meeting of the Society of NeuroInterventional Surgery; July 28August 1, 2008; Lake Tahoe, Calif.

88. Henkes $\mathrm{H}$, Miloslavski $\mathrm{E}$, Lowens $\mathrm{S}$, et al. Treatment of intracranial atherosclerotic stenoses with balloon dilatation and self-expanding stent deployment (WingSpan). Neuroradiology 2005;47:222-28

89. Jovin TG, Gupta R, Uchino K, et al. Emergent stenting of extracranial interna carotid artery occlusion in acute stroke has a high revascularization rate. Stroke 2005;36:2426-30

90. Kelly ME, Furlan AJ, Fiorella D. Recanalization of an acute middle cerebra artery occlusion using a self-expanding, reconstrainable, intracranial microstent as a temporary endovascular bypass. Stroke 2008;39:1770-73

91. Jovin TG, Gupta R, Horowitz MB, et al. Pretreatment ipsilateral regional cortical blood flow influences vessel recanalization in intra-arterial thrombolysis for MCA occlusion. AJNR Am J Neuroradiol 2007;28:164-67

92. Jo KD, Saver JL, Starkman S, et al. Predictors of recanalization with mechanical thrombectomy for acute ischemic stroke. Stroke 2008;39:599

93. Mistri AK, Robinson TG, Potter JF. Pressor therapy in acute ischemic stroke systematic review. Stroke 2006;37:1565-71

94. Lylyk P, Vila JF, Miranda C, et al. Partial aortic obstruction improves cerebra perfusion and clinical symptoms in patients with symptomatic vasospasm. Neurol Res 2005;27(suppl 1):S129-35

95. Frazee JG, Luo X, Luan G, et al. Retrograde transvenous neuroperfusion: a back door treatment for stroke. Stroke 1998;29:1912-16 